\title{
Protección del Derecho a la verdad. Fundamentos jurídicos de la Corte Interamericana de Derechos Humanos*
}

Protection of the Right to Truth. Legal grounds of the Inter-American Court of Human Rights

\author{
Proteção do Direito à verdade. Fundamentos jurídicos da Corte \\ Interamericana de Direitos Humanos
}

Recibido el 7 de diciembre de 2015. Aceptado el 6 de abril de 2016

\author{
Paola Andrea Becerra Satizabal** \\ Colombia \\ Eileen Vanessa Pava Mendoza*** \\ Colombia
}

Para citar este artículo:

Becerra Satizabal, Paola

Andrea y Pava Mendoza,

Eileen Vanessa (junio, 2016).

Protección del Derecho a la

verdad. Fundamentos jurídicos

de la Corte Interamericana de

Derechos Humanos. Ánfora,

23(40), 121-147. Universidad

Autónoma de Manizales. ISSN

0121-6538.

\section{Resumen}

Objetivo: visibilizar el reconocimiento de los fundamentos jurídicos que protegen el Derecho a la verdad, mediante su identificación y análisis en la jurisprudencia de la Corte Interamericana de Derechos Humanos. Metodología: estudio documental con enfoque cualitativo. Se buscó información en fuentes primarias y secundarias con base en dos categorías de análisis: Desarrollo teórico del Derecho a la verdad y

\footnotetext{
*Este artículo se deriva de la investigación denominada “El Derecho a laverdad: una revisión jurisprudencial de su protección por parte de La Corte Interamericana de Derechos Humanos", presentada por las autoras para optar al título de Abogadas. Universidad San Buenaventura, 2015. Se inició en el mes de marzo del año 2015 y se terminó en el mes de enero del año 2016.

2. Abogada. Universidad San Buenaventura, Colombia. Correo electrónico: pao_7s@hotmail.com

3. Abogada. Universidad San Buenaventura, Colombia. Correo electrónico: vane_pava123@hotmail.com
} 
Argumentos expuestos por la Corte IDH para proteger el derecho a la verdad. Además, se realizó un estudio de la jurisprudencia internacional. Resultados: se halló que la protección del Derecho a la verdad en la jurisprudencia de la Corte IDH se concreta mediante la protección de derechos conexos contemplados en la Convención Americana de Derechos Humanos: el derecho a las garantías judiciales, el derecho al acceso a la información, el derecho a la integridad personal, el derecho a la protección judicial. Conclusiones: el desarrollo jurisprudencial de la Corte IDH sobre el Derecho a la verdad se ha aplicado en el marco de casos sobre desapariciones forzadas y ejecuciones extrajudiciales. Los fundamentos de este Tribunal sitúan al Derecho a la verdad como una medida de reparación; como un beneficio sometido a otros derechos consagrados en la Convención Americana, con el fin de que los Estados cumplan con la obligación de investigar los hechos y juzgar a los responsables, entre otras circunstancias. En las Sentencias de la Corte puede hablarse de una autonomía condicionada del Derecho a la verdad.

Palabrasclave: Derechoa la Verdad, Protección, Impunidad, Sentencia, Reparación.

\section{Abstract}

Objective: to make clearly visible the recognition on legal grounds that protect the Right to Truth by identifying and analyzing them in the jurisprudence of the InterAmerican Court of Human Rights. Methodology: in this documentary research, with a qualitative approach, data was collected from primary and secondary sources based on two categories of analysis, namely theoretical development of the Right to Truth and Arguments of the Inter-American Court of Human Rights to protect the Right to Truth. It was also conducted a study of the international jurisprudence. Results: results showed that protection of the Right to Truth in the Jurisprudence of the Inter-American Court of Human Rights is established by protecting related rights in accordance with the American Convention on Human Rights: the right to judicial guarantees, the right to access to information, the right to humane treatment, as well as the right to judicial protection. Conclusions: the jurisprudential development of the Inter-American Court of Human Rights on the Right to Truth has been implemented in cases of forced disappearances and extrajudicial executions. The foundations of this Court place the Right to Truth as a remedial action; and as a benefit subjected to other rights under the American Convention in order to ensure the States comply with the obligation to investigate the facts and prosecute those responsible, among other circumstances. Regarding the Judgment of the Court, it is possible to refer to a conditional autonomy of the Right to Truth.

Keywords: Right to Truth, Protection, Impunity, Judgment, Reparation. 


\section{Resumo}

Objetivo: visibilizar o reconhecimento dos fundamentos jurídicos que protegem - Direito à verdade, mediante sua identificação e análise na jurisprudência da Corte Interamericana de Direitos Humanos. Metodologia: estudo documental com enfoque qualitativo. Pesquisou-se informação em fontes primarias e secundarias com base em duas categorias de análise: Desenvolvimento teórico do Direito à verdade e Argumentos expostos pela Corte IDH para proteger o direito à verdade. Além disso, realizou-se um estudo da jurisprudência internacional. Resultados: encontrou-se que a proteção do Direito à verdade na jurisprudência da Corte IDH se concreta mediante a proteção de direitos conexos contemplados na Convenção Americana de Direitos Humanos: o direito às garantias judiciais, o direito ao acesso à informação, o direito à integridade pessoal, o direito à proteção judicial. Conclusões: o desenvolvimento jurisprudencial da Corte IDH sobre o Direito à verdade tem se aplicado no marco de casos sobre desaparições forçadas e execuções extrajudiciais. Os fundamentos deste Tribunal situam ao Direito à verdade como uma medida de reparação; como um beneficio sometido a outros direitos consagrados na Convenção Americana, com a finalidade de que os Estados cumpram com a obrigação de investigar os fatos e julgar aos responsáveis, entre outras circunstancias. Nas sentenças da Corte pode falar-se de uma autonomia condicionada do Direito à verdade.

Palavras chave: Direito à Verdade, Proteção, Impunidade, Sentença e Reparação. 


\section{Introducción}

La violación a los Derechos Humanos ha sido una práctica frecuente en países en los que el Estado es uno de sus principales responsables (Caso Velásquez Rodríguez Vs. Honduras, 1988; Caso Anzualdo Castro Vs. Perú, 2009; Caso Gomes Lund y otros Vs. Brasil, 2010; Caso Gelman Vs. Uruguay, 2011; Caso Rodríguez Vera y otros (desaparecidos del Palacio de Justicia) vs. Colombia, 2014). En tal sentido, la incertidumbre de las víctimas y sus familiares ha sido motivo de análisis desde instancias del derecho internacional, donde se sientan las bases que permiten reconocer el derecho a la verdad (Amaya, 2007).

En ese proceso, la verdad ha tenido un desarrollo conceptual que pasa por diferentes perspectivas, para ligarse a los Derechos Humanos como una forma de garantizar el conocimiento de los hechos, de preservar la memoria y prevenir la impunidad (Amaya, 2007; Gonzáles, 2008). Por tales razones, el derecho a la verdad se posiciona inicialmente en el plano internacional de los Derechos Humanos y en la actualidad constituye uno de los elementos fundamentales de la justicia y la reparación en contextos de conflicto armado.

La verdad es abordada, por lo tanto, en conexidad $^{3}$ con los derechos de las víctimas y las condiciones necesarias para combatir la impunidad en las violaciones a los Derechos Humanos. El Protocolo I, adicional a los Convenios de Ginebra de 1949, es el primer instrumento internacional que abordó la verdad desde esta perspectiva, definiéndolo como el "derecho que asiste a las familias de conocer la suerte de sus miembros” (Núñez y Zuluaga, 2012, p. 217).

Tal dinámica internacional se materializó en América Latina a través de instancias como el Sistema Interamericano de Derechos Humanos, el cual se instituyó a partir de 1948 con la creación de la Carta de la OEA y la aprobación de la Declaración Americana de Derechos y Deberes del Hombre; en el marco de este momento histórico se creó en 1959 la Comisión Interamericana de Derechos Humanos (en adelante CIDH). Sin embargo, solo hasta 1969 se aprobó un tratado con fuerza vinculante: "la Convención Americana de Derechos Humanos”, que consagró derechos civiles y políticos; y ésta, a su vez, creó la

3. La mención sobre derechos en conexidad se refiere a una relación entre dos o más derechos, en la que al no protegerse el primero podría terminar afectándose el segundo. Dicha tesis de conexidad ha sido ampliamente utilizada para proteger los Derechos Económicos, Sociales y Culturales correlacionándolos con los derechos fundamentales (Arango, 2005). 
Corte Interamericana de Derechos Humanos (en adelante Corte IDH) y dotó a la CIDH de nuevas funciones, convirtiéndola en el órgano principal de la OEA.

Dicha contextualización sobre la evolución de instancias como la Corte IDH es necesaria si se tiene en cuenta que fue a partir de su fallo sobre el caso Velásquez Rodríguez vs. Honduras (1988) que se dio inicio al desarrollo jurisprudencial sobre el derecho a la verdad. A partir de esta Sentencia, la Corte IDH abordó el Derecho a la verdad en situaciones de desapariciones forzadas, refiriéndose a "la verdad objetiva” como parte de la obligación del Estado de investigar violaciones de Derechos Humanos. Lo mismo, ocurrió en el caso Godínez Cruz vs. Honduras (1989) donde la Corte IDH afirmó la obligación de los Estados de investigar de manera pertinente y seria estas violaciones.

Años más tarde, la Corte IDH en la Sentencia Bámaca Velásquez vs. Guatemala (2000), estableció por primera vez el concepto expreso del Derecho a la verdad, afirmando que "el derecho a la verdad se encuentra subsumido en el derecho de la víctima o sus familiares a obtener de los órganos competentes del Estado el esclarecimiento de los hechos violatorios y las responsabilidades correspondientes, a través de la investigación y el juzgamiento que previenen los Artículos 8 y 25 de la Convención” (párr. 201). Otra Sentencia relevante es el caso de la Masacre de Mapiripán vs. Colombia (2005), ya que la Corte IDH incorpora un nuevo elemento en el derecho a la verdad, estableciendo un "plazo razonable” en la obligación de investigar del Estado violaciones de Derechos Humanos.

Así las cosas, la Corte IDH protege el Derecho a la verdad, pese a que no está consagrado de manera expresa en la Convención Americana de Derechos Humanos. En ese sentido, surge el interrogante ¿Cuáles han sido los fundamentos jurídicos de la Corte Interamericana de Derechos Humanos para proteger el derecho a la verdad?

Por lo tanto, el objetivo de este artículo es contribuir al reconocimiento de los fundamentos jurídicos que protegen el Derecho a la verdad, mediante su identificación y análisis en la jurisprudencia de la Corte Interamericana de Derechos Humanos, una de las principales instancias que intervienen en su protección desde el poder sancionatorio y competencia que le imprimen los tratados y convenciones ratificados por los Estados. De esta manera, el desarrollo de esta investigación aportará, en el ámbito regional, conocimiento para las víctimas y los operadores de justicia que son los encargados de reconocer este Derecho en la sociedad e implementar la correcta incorporación de los estándares internacionales. 


\section{Metodología}

Se desarrolló un estudio de tipo cualitativo, teniendo como fuentes las normas internacionales y la jurisprudencia regional contenida en Sentencias de la Corte IDH, documentos oficiales de la Organización de Naciones ${ }^{3}$ Unidas, artículos de revistas especializadas, libros en versión digital e impresa. Su análisis estuvo orientado por dos categorías: el desarrollo teórico del Derecho a la verdad y los argumentos expuestos por la Corte IDH para proteger el derecho a la verdad.

Para analizar la primera categoría se tomó como referencia el esquema por etapas propuesto por Quintana (2006) para llevar a cabo un análisis documental: rastreo e inventario de los documentos existentes y disponibles; clasificación de los documentos identificados; selección de los documentos más pertinentes para los propósitos de la investigación; lectura en profundidad del contenido de los documentos seleccionados para extraer elementos de análisis; lectura cruzada y comparativa de los documentos en cuestión.

El estudio de la segunda categoría se realizó mediante una línea jurisprudencial teniendo en cuenta orientaciones metodológicas de López (2006) y Bustamante $(2014)^{5}$, aplicando el análisis de ingeniería reversa en el cual se tienen en cuenta soluciones jurisprudenciales precedentes (fallos anteriores), identificando las sentencias que han sido citadas en su ratio decidend $i^{6}$, entendiendo el precedente no como aquel de aceptación técnica de fuerza vinculante para jueces descrito por López (2006), sino como un argumento que se presenta repetida y uniformemente en la jurisprudencia de la Corte IDH conforme a la adaptación de Bustamante (2014) a dicha metodología. Esto conllevó la construcción de un nicho citacional

4. Dicha metodología consiste en definir el patrón fáctico o problema jurídico a analizar, identificar el punto arquimédico o punto de partida de análisis que está representado en el fallo más reciente que haga referencia a dicho problema, seguidamente se procede a aplicar la ingeniería reversa que consiste en identificar las sentencias que han sido citadas por el Tribunal en la sentencia arquimédica. Hecho esto se identifican aquellas sentencias que están presentes en cada una de las sentencias citadas en la sentencia arquimédica, esto constituye el nicho citacional. Al realizar este ejercicio se van identificando las sentencias que reiteradamente han sido citadas por la Corte y se procede a analizarlas para comprender el porqué de su relevancia, bien sea porque han establecido cambios jurisprudenciales u otros aspectos significativos.

5. La metodología expuesta por Diego López Medina tiene como finalidad comprender la doctrina constitucional vigente a través del estudio técnico de la citación jurisprudencial; sin embargo, Bustamante (2014) adecuó sus postulados para comprender las dinámicas de otro sistema jurídico como el Interamericano. Es decir, permitió adecuar la metodología dirigida al análisis de jurisprudencia la Corte Constitucional colombiana a la emitida por instancias como la Corte IDH.

6. El ratio decidendi comprende los fundamentos jurídicos en que el tribunal basa su decisión, son además reglas o principios con fuerza vinculante. 
en el cual se tuvo como patrón fáctico objeto de estudio, el reconocimiento taxativo del Derecho a la verdad en las Sentencias de dicha Corte.

Para tal fin, el punto de partida del análisis o Sentencia arquimédica ${ }^{7}$, fue la Sentencia del Caso Rodríguez Vera y otros (desaparecidos del Palacio de Justicia) vs. Colombia (2014). En ella se reconoce taxativamente el derecho de las víctimas a conocer la verdad (Consideraciones de la Corte, literal B.7, p.171) y es uno de los fallos más recientes.

Acudiendo al análisis de la ingeniería reversa, se identificaron en el Caso Rodríguez Vera y otros (desaparecidos del Palacio de Justicia) vs. Colombia (2014), trece Sentencias (o Sentencias de primer nivel) en las que Corte IDH apoyó sus pronunciamientos sobre el derecho a la verdad: Caso Osorio Rivera y Familiares Vs. Perú (2013); Caso Masacres de El Mozote y lugares aledaños Vs. El Salvador (2012); Caso Uzcátegui y otros vs. Venezuela (2012); Caso Gelman vs. Uruguay (2011); Caso Gomes Lund y otros ("Guerrilha do Araguaia") vs. Brasil. (2010); Caso Chitay Nech y otros vs. Guatemala (2010); Caso De la Masacre de las Dos Erres Vs. Guatemala (2009); Radilla Pacheco vs. México (2009); Caso Anzualdo Castro vs. Perú (2009); Caso de la Masacre de la Rochela vs. Colombia (2007); Caso Almonacid Arellano y otros vs. Chile (2006); Caso Baldeón García vs. Perú (2006); Caso Velásquez Rodríguez vs. Honduras (1988). A partir de la revisión de dichas Sentencias y de la citación que se encontraba en cada una de ellas relacionada con el Derecho a la verdad, se pudo establecer como Sentencia fundacional ${ }^{8}$ la que corresponde al Caso Velásquez Rodríguez Vs. Honduras (1988), siendo el principal antecedente del reconocimiento del Derecho a la verdad en la jurisprudencia de la Corte IDH. Se encontró también Sentencias hito de la línea ${ }^{9}$; es decir, aquellas que de manera reiterada han sido utilizadas por la Corte IDH para apoyar sus argumentos, como las siguientes: Caso Almonacid Arellano y otros Vs. Chile (2006); Caso de la Masacre de la Rochela Vs. Colombia (2007); Caso Anzualdo Castro Vs. Perú (2009); Caso Gomes Lund y otros ("'Guerrilha do Araguaia"') Vs. Brasil (2010); Caso Gelman Vs. Uruguay (2011); Caso Myrna Mack Chang Vs. Guatemala (2003).

\footnotetext{
7. Corresponde a uno de los fallos más recientes en donde logre identificarse claramente el patrón fáctico o problema jurídico analizado.

8. Son aquellas que debido a la novedad del tema tratado, crean la línea jurisprudencial.

9. Son aquellas sentencias que realizan cambios fuertes de jurisprudencia dentro de la línea.
} 


\section{Resultados}

Los resultados se presentan en tres apartados. El primero muestra el desarrollo teórico del derecho a la verdad, evidenciando sus antecedentes, evolución histórica y elementos estructurales. En el segundo, se relacionan los casos contenciosos de la Corte IDH sobre el derecho la verdad, a través de la línea jurisprudencial sobre los mismos, la identificación y análisis de los fundamentos jurídicos en ellos contenidos. El último apartado, presenta los resultados del análisis realizado a los argumentos expuestos por la Corte IDH para proteger el Derecho a la verdad, a partir de los fundamentos identificados en el segundo apartado.

\section{Desarrollo teórico del derecho a la verdad}

La revisión de los antecedentes del Derecho a la verdad, da cuenta de su desarrollo a partir del Derecho Internacional Humanitario, situando la proclamación en 1977 del Protocolo I adicional a los Convenios de Ginebra de 1949, como el primer texto en el que se reconoce el derecho de las víctimas de conflictos armados internacionales de "conocer la suerte de sus miembros"; refiriéndose especialmente a personas desaparecidas y fallecidas (Núñez y Zuluaga, 2012; Fajardo, 2012).

Consecuentemente, con el desarrollo de la doctrina y jurisprudencia internacionales, se generó la obligación de los Estados de buscar a las personas desaparecidas, investigar y castigar a los responsables de graves violaciones a los Derechos Humanos (Núñez y Zuluaga, 2012; CIDH, 2014). Evidencia de ello, fue el fallo de la Corte Interamericana de Derechos Humanos en 1988 sobre el caso Velásquez Rodríguez vs Honduras ${ }^{10}$, con el cual se sentó un precedente frente al deber jurídico e intransferible del Estado de investigar la existencia de la vulneración y garantizar el acceso a una verdad objetiva (Torreblanca, 2012).

De esa manera, el fenómeno de la desaparición forzada y su estudio desde el Derecho Internacional Humanitario, dieron lugar al reconocimiento del Derecho a la verdad en 2005 como norma internacional consuetudinaria, a través de la Resolución 2005/66 adoptada por la Comisión de Derechos Humanos de la ONU (Navarrete, s.f.). Dicho reconocimiento, permite identificar dos perspectivas de análisis que guardan coherencia con la evolución jurídica del Derecho a la verdad

10. Corte Interamericana de Derechos Humanos. Caso Velásquez Rodríguez Vs. Honduras. Sentencia de 21 de julio de 1989. Detención y posterior desaparición del señor Ángel Manfredo Velásquez Rodríguez en la República de Honduras. 
a través del Derecho Internacional Humanitario: la lucha contra la impunidad y las medidas de reparación a las víctimas.

Desde la perspectiva de la lucha contra la impunidad, se ha logrado codificar el Derecho a la verdad a través de una serie de principios que orientan a los Estados frente a las medidas que garantizan su protección. Tal conjunto de principios, ha sido el resultado de diferentes estudios direccionados por la Organización de Naciones Unidas, entre los cuales se destacan los siguientes (Comisión Colombiana de Juristas, 2007): el estudio de Joinet (1996); el estudio de Orentlicher (2004); el informe de Orentlicher (2005).

Desde la perspectiva del derecho de las víctimas a obtener reparaciones, la definición de los principios internacionales ha sido el resultado de un proceso de construcción, a partir de estudios que han contribuido a la adaptación gradual de los mecanismos tendientes a garantizar el Derecho a la verdad como una medida de satisfacción, conforme a la evolución de los conflictos, del Derecho Internacional Humanitario y de la confluencia internacional. Dentro de dichos estudios, cabe mencionar los siguientes (Comisión Colombiana de Juristas, 2007): el estudio y directrices de van Boven de 1993, 1996 y 1997; las directrices de Bassiouni (1999); el informe de Salinas (2005).

Es así como considerar el desarrollo teórico del Derecho a la verdad, remite a la evolución histórica que la idea de verdad en sí misma ha tenido; una idea que se ha entendido de diferentes maneras a través de los años y a la que la historia de la ciencia le ha permitido evaluar las transformaciones en el pensamiento humano, en su percepción del mundo y la realidad (Muchinik, 2003). En esa evolución de la idea de verdad, hay momentos icónicos que influyeron en la concepción de la verdad como un derecho. Entre tales momentos se encuentran periodos históricos que evidencian un antes y un después en el conocimiento acerca del hombre, de las ideas de verdad y la realidad como consecuencia de rupturas epistemológicas (Muchinik, 2003).

La verdad, entonces, llegó a ser para el derecho, fundamento filosófico y requisito condicionante de la legitimidad de los fallos, haciéndose indispensable para impartir justicia y desligándose de esa verdad que solamente logra generar elementos relevantes para la aplicación de las normas, para trascender a un concepto del derecho a saber la verdad que llega a posicionarse a partir del derecho internacional en los Convenios de Ginebra (Fajardo, 2012). 
En ese contexto, la verdad se analiza en conexidad con los derechos de las víctimas y las condiciones necesarias para combatir la impunidad en las violaciones a los Derechos Humanos. El Protocolo I, adicional a los Convenios de Ginebra de 1949, es el primer instrumento internacional que abordó la verdad desde esta perspectiva, definiéndolo como el "derecho que asiste a las familias de conocer la suerte de sus miembros" (Núñez y Zuluaga, 2012, p.217).

De esta manera, al Derecho a la verdad le fue atribuido un sustento jurídico a la luz de los Artículos 32 y 33 de dicho Protocolo, dando paso a la definición de los estándares de Derechos Humanos y principios que fueron definidos por la Organización de Naciones Unidas en el año 2005 (Comisión Colombiana de Juristas, 2007). A partir de dichos estándares y principios, la verdad se ha concebido como un derecho que debe ser reconocido por los Estados y garantizado a las víctimas de violaciones a los Derechos Humanos y al Derecho Internacional Humanitario. En ese sentido, el derecho a la verdad se estudia desde Naciones Unidas bajo dos perspectivas y consecuentemente, dos grupos de principios (Comisión Colombiana de Juristas, 2007):

1. Conjunto de principios actualizado para la protección y la promoción de los derechos humanos mediante la lucha contra la impunidad ${ }^{11}$.

2. Principios y directrices básicos sobre el derecho de las víctimas de violaciones manifiestas de las normas internacionales de derechos humanos y de violaciones graves del derecho internacional humanitario a interponer recursos y obtener reparaciones ${ }^{12}$.

Cada campo de principios cuenta con lineamientos específicos para su implementación por los Estados miembros dentro de la obligación general que tienen de prevenir, investigar y sancionar las violaciones de derechos humanos. En todo ese proceso, son ejes transversales de cara a las víctimas "el derecho a saber (o el derecho a la verdad); el derecho a la justicia; y el derecho a obtener reparaciones" (Comisión Colombiana de Juristas, 2007, p.18.)

Ahora, el acervo jurídico internacional sobre derechos humanos, hace énfasis especial en el reconocimiento de la verdad como un elemento fundamental para que las víctimas, las familias y la sociedad puedan conocer las circunstancias

11. Comisión de Derechos Humanos de la Organización de Naciones Unidas (ONU), Resolución sobre impunidad, número 2005/81 
particulares de los hechos violatorios de los derechos humanos y los autores de los mismos. Por tanto, la justicia es un concepto que va unido al derecho a la verdad pues entrega a las víctimas y sus familias la posibilidad de ser partícipes de los procesos penales en los cuales se juzgan los autores y sus cómplices y que las penas y sanciones impuestas sean las que considere la ley.

En relación con los elementos estructurales del Derecho a la verdad a partir de la bibliografía y jurisprudencia consultada, se identificaron tres elementos de consideración sobre el Derecho a la verdad: su estructura jurídica fundamental, sus dimensiones y los mecanismos de búsqueda de la verdad. En cuanto a su estructura jurídica, autores como Fajardo (2012) mencionan que este derecho cuenta con un sustento jurídico que contempla, principalmente, los principios de la ONU y las Sentencias de la Corte Interamericana de Derechos Humanos. Sin embargo, la discusión doctrinal sobre este derecho gira en torno a la inexistencia de instrumentos de hard law $w^{13}$ que lo consagren de manera taxativa, sin desconocer lo establecido en el Convenio de Ginebra sobre el derecho de las familias de personas desaparecidas y fallecidas en conflictos armados.

Por tanto, su estructura jurídica fundamental remite a elementos del derecho consuetudinario, siendo una conclusión respaldada por instancias como el Comité Internacional de la Cruz Roja (Comisión Colombiana de Juristas, 2012). Contrastando esta postura, autores como Naqvi (2006) advierten que el carácter consuetudinario del Derecho a la verdad aún carece de elementos que a la luz de indicadores de los derechos humanos consuetudinarios, puedan probar dicho carácter; no obstante, se refiere al desarrollo jurisprudencial que se ha dado a través del Derecho Internacional Humanitario aduciendo que

(...) el efecto acumulativo de esas decisiones, sumado a la difundida práctica de instituir mecanismos destinados a descubrir la verdad en países donde se han cometido crímenes graves, así como algunas leyes nacionales, y la reiteración constante, por parte de los órganos internacionales y nacionales, de la importancia de conocer la verdad, son indicios de la aparición de algo que se aproxima a un derecho consuetudinario (aunque con diferentes formas) (Naqvi, 2006, p.27).

13. Este concepto guarda relación con instrumentos o prácticas generales de carácter obligatorio cuyo incumplimiento puede ser exigido por las vías institucionales de solución de conflictos y derivar en la responsabilidad internacional del Estado. 
Por lo tanto, a pesar de que el Derecho a la verdad ha ganado reconocimiento a través del soft law $w^{14}$, no se puede desconocer que su estructura jurídica se fundamenta en instrumentos internacionales que son de amplio reconocimiento por los Estados que han ratificado los diferentes Convenios en materia de protección y defensa de los Derechos Humanos y del Derecho Internacional Humanitario.

De otra parte, en lo que concierne a las dimensiones individual y colectiva del Derecho a la verdad, se parte de considerar que "para garantizar los derechos del futuro, la sociedad debe aprender de los abusos cometidos en el pasado" (Naqvi, 2006, p.16), perspectiva ésta adoptada por la Comisión Interamericana de Derechos Humanos que ha permitido inferir el Derecho a la verdad tanto para los familiares de las víctimas como para la sociedad en su conjunto, basándose en derechos refrendados en la Convención Americana sobre Derechos Humanos (Naqvi, 2006; Fajardo, 2012; Comisión Colombiana de Juristas, 2012).

Finalmente, en cuanto a los mecanismos de búsqueda de la verdad, estos guardan coherencia con la caracterización que se ha dado a este derecho a través del derecho internacional, relacionándolo principalmente con: Derecho la verdad como prevención de la impunidad y Derecho a la verdad o derecho a saber, como un mecanismo de reparación.

En ambos casos, las medidas y mecanismos que conducirían al goce efectivo del derecho de las víctimas, sus familias y la sociedad a la verdad, se encuentran relacionadas en los dos grupos de principios definidos por la $\mathrm{ONU}^{15}$ y que han sido citados anteriormente. En cuanto al Derecho a la verdad y su conexidad con el derecho a saber en la lucha contra la impunidad, los mecanismos contemplan en primera instancia la aplicación de cuatro principios generales por parte de los Estados: el derecho inalienable a la verdad, el deber de recordar, el derecho de las víctimas a saber y garantías para hacer efectivo el derecho a saber (Comisión Colombiana de Juristas, 2007).

\footnotetext{
14. El derecho blando comprende una serie de actos, no homogéneos en cuanto origen y naturaleza, que a pesar de estar privados de efectos jurídicos vinculantes resultan, a través de distintas vías, jurídicamente relevantes. Se les considera normas ligeras, dúctiles o blandas, en el sentido de falta de eficacia obligatoria per se, carencia que no impide, sin embargo, que gocen de cierta eficacia jurídica, gracias a la influencia que ejercen derivada de su capacidad de persuasión sobre los Estados y los individuos (Hoyos, 2011, p. 3).

15. Conjunto de principios actualizado para la protección y la promoción de los Derechos Humanos mediante la lucha contra la impunidad. Principios y directrices básicos sobre el derecho de las víctimas de violaciones manifiestas de las normas internacionales de Derechos Humanos y de violaciones graves del derecho internacional humanitario a interponer recursos y obtener reparaciones.
} 
Sumado a ello, contemplan el establecimiento de comisiones de investigación, la definición clara de sus funciones y del alcance de su mandato, incluyendo mecanismos extrajudiciales como las comisiones de verdad (Comisión Colombiana de Juristas, 2007). Así también, establecen medidas de preservación y consulta de los archivos a fin de determinar las violaciones.

El Derecho a la verdad como medida de reparación y los mecanismos para su efectivo goce, se analizar desde el derecho de las víctimas a la información sobre las violaciones y el derecho de las víctimas a recibir reparaciones por el daño sufrido, siendo la verdad una medida de satisfacción (Comisión Colombiana de Juristas, 2007).

Lo anterior da cuenta, no solamente del desarrollo teórico que ha tenido el Derecho a la verdad, sino también su estudio y reconocimiento a través de instrumentos y documentos doctrinales del derecho internacional, por lo que la revisión de fundamentos jurídicos que se condensan en casos como los sancionados por la Corte IDH, es un paso necesario para avanzar en el conocimiento de la verdad como derecho y las medidas existentes para protegerlo.

\section{Los casos contenciosos de la Corte Interamericana de Derechos Humanos sobre el Derecho a la verdad y sus fundamentos juridicos}

Para avanzar en el conocimiento de la verdad como derecho y las medidas existentes para protegerlo, las sanciones impartidas por la Corte IDH representan un compendio de lineamientos, exigencias y deberes que deben acatar los Estados para proteger el Derecho a la verdad. En tal sentido, en este apartado se presentan los hallazgos del estudio de los casos contenciosos de dicho Tribunal.

Para llevar a cabo este estudio, inicialmente se realizó el análisis jurisprudencial, teniendo en cuenta orientaciones metodológicas de López (2006) y Bustamante (2014), descritas anteriormente en el apartado de la Metodología. En el proceso de análisis preliminar de las Sentencias, se fueron identificando algunos de los argumentos relevantes citados en varias ocasiones por la Corte IDH sobre el derecho a la verdad, dando cuenta de la orientación hacia la prevención de la impunidad, hacia las medidas de reparación, hacia la incorporación de elementos establecidos en los principios e instrumentos de la ONU sobre desapariciones forzadas; y hacia el reconocimiento de derechos de las víctimas y sus familias que se posicionan como conexos a la verdad, como son las garantías judiciales y la integridad psíquica y moral. 
Ahora bien, la identificación y análisis de los fundamentos jurídicos utilizados por la Corte IDH para proteger el Derecho a la verdad, se realizó teniendo en cuenta el contenido de las Sentencias arquimédica, fundacional e hito de la línea, las cuales se presentan a continuación siguiendo un orden cronológico de la más antigua a la más reciente; esto permitió trazar una línea de tiempo que evidencia el desarrollo de los fundamentos jurídicos de la Corte IDH y/o la permanencia de reglas y subreglas ${ }^{16}$ que a través de los años han permanecido vigentes a partir de casos emblemáticos.

\section{Caso Velásquez Rodríguez Vs. Honduras (1988)}

Este caso se refiere a la responsabilidad internacional del Estado hondureño por la detención y posterior desaparición de Ángel Manfredo Velásquez Rodríguez como consecuencia de hechos ocurridos entre 1981 y 1984 y donde desaparecieron más de 100 personas. Con este caso, el fenómeno de las desapariciones forzadas se posiciona como una forma compleja de violación de los derechos humanos, que además tiene el carácter de ser múltiple y continuada.

Respecto al Derecho a la verdad, la Corte, en esa época, reconoció “el derecho de los familiares de la víctima de conocer cuál fue el destino de ésta y, en su caso, dónde se encuentran sus restos” (párr.181), aduciendo además que el Estado debe satisfacer con los medios a su alcance el deber de investigar mientras se mantenga la incertidumbre sobre la suerte final de la persona desaparecida. En los puntos resolutivos, la Corte IDH indicó la violación del Estado hondureño a los Artículos 4, 5 y 7 de la Convención que protegen los derechos a la libertad personal, a la integridad personal y a la vida; todos ellos en relación con el 1.1 de la misma. Sobre el artículo 1.1 de la Convención, aclara la Corte que este se ve violentado por los Estados que no disponen todos los recursos necesarios y efectivos para proteger los derechos reconocidos en la Convención y por tanto, indica que

Como consecuencia de esta obligación los Estados deben prevenir, investigar y sancionar toda violación de los derechos reconocidos por la Convención y procurar, además, el restablecimiento, si es posible, del derecho conculcado y, en su caso, la reparación de los daños producidos por la violación de los derechos humanos (Caso Velásquez Rodríguez Vs. Honduras, 1988, párr.166)

16. Corresponden a la argumentación que soporta la resolución (fallo) de un caso en concreto. 
Este, a la luz de la línea jurisprudencial analizada, fue el principal antecedente del reconocimiento del derecho a la verdad en la jurisprudencia de la Corte IDH,citado desde entonces para apoyar sus argumentos desde el "derecho a conocer".

\section{Caso Myrna Mack Chang Vs. Guatemala (2003).}

En esta Sentencia, fue juzgada la responsabilidad del Estado de Guatemala en la ejecución extrajudicial de Myrna Mack, como también de contrarrestar la impunidad presente en el caso ante la ineficiente investigación de los hechos, juzgamiento y sanción de los responsables. En las peticiones de la parte demandante, se solicita claramente respetar el derecho de la familia de la víctima a conocer la verdad y a que después del juicio nadie niegue lo sucedido. En este caso, la Corte IDH manifestó que

Si las autoridades permiten y toleran el uso de esta manera de los recursos judiciales, los transforman en un medio para que los que cometen un ilícito penal dilaten y entorpezcan el proceso judicial. Esto conduce a la violación de la obligación internacional del Estado de prevenir y proteger los derechos humanos y menoscaba el derecho de la víctima y de sus familiares a saber la verdad de lo sucedido, a que se identifique y se sancione a todos los responsables y a obtener las consecuentes reparaciones (Caso Myrna Mack Chang Vs. Guatemala, 2003, párr. 211 ).

En dicho fallo, los fundamentos jurídicos utilizados por la Corte IDH convocan la violación del estado guatemalteco de los Artículos 8 y 25, en relación con el numeral 1.1 de la Convención Americana de Derechos Humanos, como consecuencia de la deficiente conducción de los procesos judiciales.

\section{Caso Almonacid Arellano y otros Vs. Chile (2006)}

En este caso la Corte IDH estudió la responsabilidad internacional del Estado de Chile por la falta de investigación y sanción de los responsables de la ejecución extrajudicial del señor Luis Alfredo Almonacid Arellano. Finalmente, la Corte consideró que hubo incumplimiento de los deberes generales contenidos en los Artículos 1.1 y 2 de la Convención Americana y violación de los Artículos 8 y 
25 de la misma (Garantías judiciales y protección judicial, esclarecimiento de los hechos violatorios y las responsabilidades correspondientes, a través de la investigación y el juzgamiento).

Para la Corte IDH, este incumplimiento se dio a partir del Decreto Ley No. 2.191, el cual concedía amnistías a los implicados en delitos acontecidos durante el estado de sitio y que no se encontraran sometidos a procesos o condenas. Dado que, dicho instrumento obstaculizaba la investigación, juzgamiento y sanción de los responsables de violaciones de Derechos Humanos, y por tanto dejaba impune el caso vulnerando los derechos de Luis Alfredo Almonacid Arellano y sus familiares que por más de 20 años habían buscado justicia.

En este caso, el Derecho a la verdad debió garantizarse a través del deber del Estado de investigar, determinar y sancionar a los responsables de los crímenes de lesa humanidad, viéndose vulnerado con la aplicación de leyes de amnistía que por demás, desconocieron que a este tipo de delitos no se puede conceder amnistía según lo preceptuado en el Derecho Internacional (Caso Almonacid Arellano y otros Vs. Chile, 2006, párr.115).

\section{Caso de la Masacre de la Rochela Vs. Colombia (2007)}

En este caso se responsabiliza internacionalmente al Estado colombiano por la falta de investigación y sanción de los responsables de la ejecución extrajudicial de doce personas y lesiones a otras tres por parte de grupos paramilitares.

Respecto al Derecho a la verdad, cabe resaltar que el Estado colombiano expresó que este derecho no podía invocarse como un derecho autónomo, apoyándose en la premisa de que la Corte IDH había indicado en fallos anteriores que este derecho se encuentra subsumido en los Artículos 8 y 25 de la Convención. Ante lo cual la Corte manifestó que la falta de efectividad judicial se ve reflejada en la ausencia de una conclusión definitiva que permita conocer toda la verdad, así también que el derecho a la justicia debe asegurar el derecho de las víctimas y sus familiares a conocer en tiempo razonable todo lo sucedido (párr.146), y que el Derecho a la verdad se encuentra subsumido en el derecho de la víctima o de sus familiares a obtener de los órganos competentes del Estado el esclarecimiento de los hechos violatorios y las responsabilidades correspondientes, a través de la investigación y el juzgamiento que previenen los Artículos 8 y 25 de la Convención (párr.147). 
Si bien la Corte IDH no consideró en este fallo la discusión frente al Derecho a la verdad como derecho autónomo, si aclaró de manera amplia los fundamentos jurídicos que lo protegen en conexidad con el derecho a la justicia y las obligaciones que acarrean los Estados conforme a los Artículos 8 y 5 de la Convención. Sumado a esto, la Corte IDH se refirió a la dimensión colectiva del Derecho a la verdad, dentro de las obligaciones positivas inherentes al derecho a la verdad y que exigen:

-"La adopción de los diseños institucionales que permitan que este derecho se realice en la forma más idónea, participativa y completa posible” (párr.195).

-"La determinación procesal de la más completa verdad histórica posible" (párr.195).

-"La asunción del Estado de proceso de investigación como un deber jurídico propio y no como una simple gestión de intereses particulares, que dependa de la iniciativa procesal de las víctimas o de sus familiares o de la aportación privada de elementos probatorios" (párr.195).

-"Garantizar que, en todas las etapas de los respectivos procesos, las víctimas puedan formular sus pretensiones y presentar elementos probatorios y que éstos sean analizados de forma completa y seria por las autoridades antes de que se resuelva sobre hechos, responsabilidades, penas y reparaciones" (párr.195).

Además, en esta Sentencia el Tribunal menciona como subreglas las acciones que los Estados deben cumplir para satisfacer la obligación de investigar de manera efectiva, debiendo entre otras cosas:

Facilitar todos los medios necesarios para proteger a los operadores de justicia, investigadores, testigos y familiares de las víctimas de hostigamientos y amenazas que tengan como finalidad entorpecer el proceso, evitar el esclarecimiento de los hechos y encubrir a los responsables de los mismos (párr.171).

Suministrar recursos judiciales efectivos a las víctimas de violaciones de los derechos humanos (artículo 25), recursos que deben ser sustanciados de conformidad con las reglas del debido proceso legal (artículo 8.1), todo ello dentro de la obligación general, a cargo de los mismos Estados, de garantizar el libre y pleno ejercicio de los derechos reconocidos por la Convención a toda persona que se encuentre bajo su jurisdicción (artículo 1.1) (párr.145). 


\section{Caso Anzualdo Castro Vs. Perú (2009)}

Este caso se refiere a la responsabilidad internacional por la desaparición forzada de Kenneth Ney Anzualdo Castro del Servicio de Inteligencia del ejército peruano. En él se destaca la vinculación del sufrimiento de los familiares con la violación del derecho a conocer la verdad, al considerar que "la privación continua de la verdad acerca del destino de un desaparecido constituye una forma de trato cruel e inhumano para los familiares cercanos" (párr.113).

Adicional a ello, de los párrafos 116 al 119, el Tribunal precisa el derecho a conocer la verdad en casos de desapariciones forzadas, de lo cual se deduce que el derecho a la verdad, surge del derecho al acceso a la justicia, fundamentado en los artículos 1.1, 8 y 25 de la Convención Americana (párr. 116) y que el Derecho a la verdad fue reconocido en fallos anteriores sobre desapariciones forzadas (Velásquez Rodríguez vs Honduras, 1988) afirmando la existencia del derecho que asiste a los familiares de la víctima a conocer el destino de ésta, y de ser posible, el paradero de sus restos (párr.118). Les confiere además el derecho a que los hechos sean investigados y que los responsables sean procesados y, en su caso, sancionados (párr. 118); como también a ser reparados mediante el cumplimiento de la obligación de investigar.

De otra parte, como subreglas derivadas de este caso, la Corte IDH establece como exigencias para los Estados:

-Reconocer que el Derecho a la verdad en sociedades democráticas tiene un efecto social, y que dicha sociedad debe conocer los hechos sobre graves violaciones a los derechos humanos; satisfaciendo dicha expectativa colectiva.

- Investigar las violaciones de derechos humanos y divulgar públicamente los resultados de los procesos penales e investigativos.

- La "determinación procesal de los patrones de actuación conjunta y de todas las personas que de diversas formas participaron en dichas violaciones y sus correspondientes responsabilidades" (párr.119).

- Garantizar el Derecho a la verdad, teniendo la posibilidad de establecer comisiones de verdad para favorecer la construcción de la memoria histórica.

\section{Caso Gomes Lund y otros ("Guerrilha do Araguaia") Vs. Brasil (2010)}

El caso juzga la responsabilidad internacional del Estado de Brasil por las desapariciones forzadas de los miembros de la Guerrilla de Araguaia ocurridas entre 1972 y 1975, así como por la falta de investigación de tales hechos. 
En este caso, las precisiones de la Corte IDH sobre el derecho a la verdad, fueron las siguientes:

-Es deber del Estado adoptar las medidas necesarias que permitan dejar sin efecto las disposiciones legales que contravienen lo ratificado en la Convención Americana, como aquellas que impiden la investigación de los hechos, conduciendo a la perpetuación de la impunidad y la imposibilidad de que las víctimas y sus familias puedan conocer la verdad (párr.173).

-Las víctimas, sus familiares y la sociedad deben ser informados de todo lo sucedido en dichas violaciones (párr.200).

- Para garantizar el derecho a la información y consecuentemente el derecho a la verdad, los poderes públicos deben actuar de buena fe y proveer la información necesaria y requerida en el esclarecimiento de los hechos (párr.211).

- El derecho del acceso a la justicia debe asegurar el conocimiento de la verdad de los hechos en un tiempo razonable, evitando que se violen las garantías judiciales (párr.219).

-"La privación al acceso a la verdad de los hechos acerca del destino de un desaparecido constituye una forma de trato cruel e inhumano para los familiares cercanos" (párr.240).

Como rasgo relevante para el análisis, este caso aporta la referencia al artículo 13 de la Convención, en relación con el derecho a buscar y recibir información; representando un pronunciamiento de la Corte en el cual se reconoce una violación autónoma del derecho a la verdad ${ }^{17}$. Esto al considerar, que presenta una variación frente a la jurisprudencia precedente en donde siempre había sido considerado, solamente, como un derecho subsumido en los artículos 8 y 25 de la Convención.

A esto, se suma la subregla frente a la investigación efectiva que deben adelantar los estados y que exige el deber de establecer "un marco normativo adecuado para desarrollar la investigación, lo cual implica regular como delito autónomo en sus legislaciones internas la desaparición forzada de personas, puesto que la persecución penal es un instrumento adecuado para prevenir futuras violaciones de esta naturaleza” (párr.109).

17. El reconocimiento de esta violación autónoma del derecho a la verdad, es reiterado por la Corte en Sentencias posteriores como la del Caso Rodríguez Vera y otros (desaparecidos del Palacio de Justicia) vs. Colombia (2014), párrafo 509. 


\section{Caso Gelman Vs. Uruguay (2011)}

En esta Sentencia, la Corte IDH juzgó la responsabilidad internacional del Estado uruguayo por la desaparición forzada de María Claudia García Iruretagoyena de Gelman, así como de la supresión y sustitución de identidad de María Macarena Gelman García. En lo que concierne al derecho a la verdad, la Corte IDH sostuvo que:

La satisfacción de la dimensión colectiva del derecho a la verdad exige la determinación procesal de la más completa verdad histórica posible (...)(párr.192)

Las leyes de amnistía, en casos de graves violaciones a los derechos humanos, son manifiestamente incompatibles con la letra y el espíritu del Pacto de San José, pues infringen lo dispuesto por sus artículos 1.1.y 2, es decir, en cuanto impiden la investigación y sanción de los responsables de las violaciones graves de los derechos humanos y, consecuentemente, el acceso de las víctimas y sus familiares a la verdad (...) (párr.226).

Toda persona, incluyendo los familiares de las víctimas de graves violaciones a derechos humanos, tiene, de acuerdo con los artículos 1.1, 8.1, 25, así como en determinadas circunstancias al Artículo 13 de la Convención, el derecho a conocer la verdad, por lo que aquéllos y la sociedad toda deben ser informados de lo sucedido (...) (párr. 243).

\section{Caso Rodríguez Vera y otros (desaparecidos del Palacio de Justicia) vs. Colombia (2014).}

Esta sentencia juzga la responsabilidad internacional del Estado colombiano por las desapariciones forzadas, ejecuciones extrajudiciales, detención y tortura que tuvieron lugar o fueron consecuencia de la toma y retoma de Palacio de Justicia en 1985. Sobre el derecho a la verdad, la Corte ratificó sus fundamentos anteriores, donde este derecho es abordado a través de otros derechos consagrados en los artículos 8 y 25 de la Convención:

(...) en el presente caso el derecho a conocer la verdad se encuentra subsumido fundamentalmente en el derecho de las víctimas o sus familiares a obtener de los órganos competentes del Estado el esclarecimiento de los hechos violatorios y las responsabilidades correspondientes, a través de la investigación y el juzgamiento que provienen de los artículos 8 y 25 de la Convención, lo cual constituye además una forma de reparación (párr. 511). 
Al respecto y por considerarlo relevante para el análisis, es menester traer a colación el voto concurrente del Juez Eduardo Ferrer Mac-Gregor Poisot (2014), anexo a la Sentencia de dicho caso. En su voto, el Juez dio a conocer a la Corte la necesidad de reconocer el Derecho a la verdad como derecho autónomo ${ }^{18}$ en el Sistema Interamericano de Derechos Humanos, partiendo del precedente donde este Tribual declaró la violación autónoma del Derecho a la verdad (Caso Gomes Lund y otros ("Guerrilha do Araguaia") Vs. Brasil, 2010), tratándose igualmente de un caso de desaparición forzada en donde instituciones del Estado habían entorpecido los procesos de investigación al no aportar la información necesaria, situación que la misma Corte manifestó se había presentado en el caso colombiano (párrafo 510).

Al respecto, el Juez convoca a considerar por qué en el caso del Palacio de Justicia pese a que la Corte IDH se remite al fallo del Caso Gomes Lund y lo usa como preámbulo para abordar lo concerniente al Derecho a la verdad; termina aclarando que en el caso colombiano el derecho a la verdad está "fundamentalmente" subsumido en los artículos 8 y 25 de la Convención. Por lo que, el Juez considera que la Corte debe "reconsiderar sus criterios" sobre el derecho a la verdad como derecho autónomo e independiente, puesto que la falta de claridad al respecto conduce al desconocimiento de su contenido, dimensiones y verdaderos alcances. Así también que dicho derecho es ampliamente reconocido como un derecho autónomo en diferentes instrumentos internacionales y ordenamientos jurídicos internos, por lo que su desconocimiento, redunda de una “desnaturalización” del derecho en sí (Ferrer, 2014).

Por todo lo anterior, puede decirse que los fundamentos jurídicos utilizados por la Corte IDH sobre el Derecho a la verdad, han sido desde 1988, los Artículos 1.1, 8, 13 y 25 de la Convención Americana de Derechos Humanos, relacionados con las obligaciones de los Estados frente la protección de los Derechos Humanos, el derecho a las garantías judiciales, el derecho a la libertad de pensamiento y expresión (libertad de buscar, recibir y difundir informaciones) y el derecho a la protección judicial, respectivamente.

Su fundamentación, principalmente aquella basada en la consideración de la violación de los Artículos 8 y 25, está presente en casi todas las Sentencias estudiadas, siendo el marco donde el Derecho a la verdad se encuentra "subsumido" y que se garantiza mediante la protección del derecho de la víctima o de sus

18. Un derecho autónomo es aquel cuyo contenido, dimensiones y alcances están definidos y protegidos claramente a través de conceptos, principios y normas. 
familiares a obtener de los órganos competentes del Estado el esclarecimiento de los hechos violatorios y las responsabilidades correspondientes, a través de la investigación y el juzgamiento.

Solamente hasta el año 2010, con el fallo del caso Gomes Lund, se presentó una variación en los fundamentos de la Corte, refiriéndose a la violación autónoma del Artículo 13 de la Convención, relacionado con la libertad de buscar, recibir y difundir información que poseen las víctimas.

\section{Análisis de los argumentos de la Corte Interamericana de Derechos Hu- manos para proteger el derecho a la verdad}

Con base en la información obtenida hasta el momento es posible afirmar que los argumentos de la Corte IDH sobre este derecho han girado en torno a la prevención de la impunidad y de mecanismos que la potencian como son las leyes de amnistía, el derecho a las garantías judiciales, la dimensión colectiva de la verdad, la obligación el estado de investigar y la verdad como medida de reparación. En todo ello, quizás el evento más relevante a la luz de la revisión jurisprudencial, tiene que ver con el reconocimiento autónomo del derecho a la verdad, sobre la cual, si bien se considera que en diferentes instrumentos internacionales adquiere este carácter; en las Sentencias de la Corte puede hablarse de una autonomía condicionada.

Dicha apreciación parte de considerar que para que este Tribunal reconozca la violación autónoma de este derecho, el caso debe satisfacer "determinadas circunstancias" que según lo expresado por la Corte consisten en las acciones determinadas que interpongan los familiares solicitando puntualmente la protección del derecho consagrado en el Artículo 13 de la Convención, esto teniendo en cuenta lo expresado por dicho Tribunal en la cita 301, párrafo 243 del Caso Gelman vs Uruguay (2011) y que versa sobre lo siguiente: "En el Caso Gomes Lund y otros, la Corte observó que, de conformidad con los hechos del mismo, el derecho a conocer la verdad se relacionaba con una acción interpuesta por los familiares para acceder a determinada información, vinculada con el acceso a la justicia y con el derecho a buscar y recibir información consagrado en el Artículo 13 de la Convención Americana, por lo cual analizó aquel derecho bajo esta norma”.

Por lo tanto, si bien el Derecho a la verdad goza de un amplio discurrir jurisprudencial en las Sentencias de la Corte IDH que lo reconoce fundamentalmente al considerar la violación de derechos como las garantías 
judiciales, no cuenta con argumentos sólidos o ampliamente analizados, discutidos y socializados que contribuyan a su reconocimiento como derecho autónomo. Pues si bien se tiene claridad sobre los beneficios de conocer la verdad sobre los hechos y responsables de las violaciones a los Derechos Humanos, bien sea como consecuencia de procesos de investigación que aportan a la justicia, como mecanismo que contribuye a terminar con la incertidumbre de las víctimas y sus familias, como mecanismo de contribución a la construcción de la memoria, o como medida de reparación; finalmente termina siendo eso, un "mecanismo" o una "medida", sin que se proteja claramente la verdad como un derecho inquebrantable de las víctimas y sus familias.

Cabe advertir que no se pretende con ello desconocer el amplio desarrollo jurisprudencial internacional que existe sobre el derecho a la verdad, por el contrario, se espera contribuir a la reflexión sobre la necesidad de considerar tesis como la propuesta por Ferrer (2014) en su voto concurrente del caso del Palacio de Justicia y aquellos que igualmente propendan por la claridad necesaria sobre la verdad como derecho.

\section{Conclusiones}

Teniendo en cuenta los objetivos se describen las principales inferencias resultantes de cada uno, refiriendo inicialmente las que tiene que ver con el desarrollo teórico del Derecho a la verdad, seguidamente las que aluden a los fundamentos jurídicos identificados en los Casos contenciosos de la Corte IDH sobre el derecho a la verdad. Finalmente, las que se desprenden del análisis de los argumentos utilizados por la Corte IDH en dichos casos.

En primer lugar, se concluye que el Derecho a la verdad desde una perspectiva teórica y conceptual es el resultado de la construcción conjunta entre la academia y el Derecho que lleva al segundo a un nivel de desarrollo en el que se reconoce su importancia para la construcción de la historia y la memoria de una sociedad; también en el marco jurídico que lo soporta en ámbitos jurídicos donde se hace necesaria su protección para que llegue a ser fundamento filosófico y requisito condicionante de la legitimidad de los fallos. 
Esta construcción teórica resulta concordante con los argumentos que han sido incorporados por la Corte IDH en sus fallos, dado que recopila y describe la evolución de este derecho precisamente a partir de la discusión que se ha dado en el ámbito internacional y como resultado de procesos de investigación promovidos inicialmente por Naciones Unidas, tal es el caso del estudio y directrices de van Boven de 1993, 1996 y 1997, de las directrices de Bassiouni (1999) (Comisión Colombiana de Juristas, 2007) y del informe de Salinas (2005).

En segundo lugar, el análisis jurisprudencial realizado sobre el Derecho a la verdad en las Sentencias de la Corte IDH ha permitido identificar una serie de fundamentos jurídicos que guardan coherencia con los instrumentos internacionales y estándares desarrollados por Naciones Unidas en materia de lucha contra la impunidad y el derecho de las víctimas de violaciones manifiestas de las normas internacionales de derechos humanos y de violaciones graves del derecho internacional humanitario a interponer recursos y obtener reparaciones.

Dichos fundamentos sitúan al Derecho a la verdad como una medida de reparación individual y colectiva, como beneficios que se encuentran sometidos a otros derechos, como un efecto de que los Estados cumplan con su obligación de investigar los hechos y juzgar a los responsables, entre otras circunstancias. Por lo tanto, la protección del Derecho a la verdad a partir de los fundamentos jurídicos utilizados por la Corte Interamericana de Derechos Humanos, se concreta a través de la protección de derechos conexos que han sido contemplados en la Convención Americana de Derechos Humanos como son el derecho a las garantías judiciales (artículo 8), el derecho al acceso a la información (artículo 13), el derecho a la integridad personal (artículo 5), el derecho a la protección judicial (artículo 25), entre otros.

En tercer lugar, al analizar los argumentos utilizados por la Corte IDH, se encontró que el desarrollo jurisprudencial de este Tribunal sobre el Derecho a la verdad se ha dado en el marco de casos sobre desapariciones forzadas y ejecuciones extrajudiciales, atribuyendo elementos contextuales al análisis realizado por la Corte, como también “determinadas circunstancias” que han sido, o no, tenidas en cuenta para contemplar una violación autónoma de este derecho.

Sobre ese aspecto, cobra relevancia el papel de las víctimas y sus familias frente a la exigencia de derechos como el acceso a la información, consagrado en el Artículo 13 de la Convención, evidenciándose en lo mencionado anteriormente sobre el caso Gomes Lund (2010). Por lo que, el derecho de las víctimas a 
interponer recursos emerge como un posible camino que aunado al derecho a la información, puedan conducir los fallos posteriores hacia el reconocimiento evidenciable del derecho a la verdad como derecho autónomo.

Sin embargo, esta exigencia no podría ser en ningún caso, causal para eximir al Estado de garantizar el esclarecimiento de los hechos violatorios y las responsabilidades correspondientes, como bien lo ha manifestado la Corte IDH en sus diferentes fallos.

\section{Referencias}

Amaya, A. (2007). "Efecto reflejo”: la práctica judicial en relación con el derecho a la verdad en la jurisprudencia de la Corte Interamericana de Derechos Humanos. Revista Colombiana de Derecho Internacional, (10), pp.131-152.

Arango, R. (2005). Experiencia colombiana sobre la justiciabilidad de los Derechos Económicos, Sociales y Culturales. Biblioteca Jurídica Virtual del Instituto de Investigaciones Jurídicas de la UNAM. Recuperado de http:/ / biblio.juridicas.unam.mx/libros/5/2469/18.pdf

Bustamante, D. (2014). La violencia sexual como tortura. Estudio jurisprudencial en la Corte Interamericana de Derechos Humanos. Recuperado de http://www. scielo.org.co/pdf/rfdcp/v44n 121/v44n121a03.pdf

Comisión Colombiana de Juristas. (2007). Principios internacionales sobre impunidad y reparaciones. Compilación de documentos de la Organización de las Naciones Unidas (ONU).

Corte Interamericana de Derechos Humanos. (1988). Caso Velásquez Rodríguez vs. Honduras.

Corte Interamericana de Derechos Humanos. (1989). Caso Godínez Cruz vs. Honduras.

Corte Interamericana de Derechos Humanos. (2000). Caso Bámaca Velásquez vs. Guatemala. 
Corte Interamericana de Derechos Humanos. (2005). Masacre de Mapiripán vs. Colombia.

Corte Interamericana de Derechos Humanos. (2006).Caso Almonacid Arellano y otros Vs. Chile.

Corte Interamericana de Derechos Humanos. (2007). Caso de la Masacre de la Rochela Vs. Colombia.

Corte Interamericana de Derechos Humanos. (2009). Caso Anzualdo Castro Vs. Perú.

Corte Interamericana de Derechos Humanos. (2010).Caso Gomes Lund y otros ("Guerrilha do Araguaia") Vs. Brasil.

Corte Interamericana de Derechos Humanos. (2011). Caso Gelman Vs. Uruguay, 2011.

Corte Interamericana de Derechos Humanos. (2014). Caso Rodríguez Vera y otros (desaparecidos del Palacio de Justicia) vs. Colombia.

Fajardo, L. (2012). Elementos estructurales del derecho a la verdad. Revista Civilizar. Ciencias sociales y humanas, vol.12, núm. 22, pp.15-33

Ferrer, E. (2014). Voto concurrente en el caso Rodríguez Vera y Otros (Desaparecidos del Palacio de Justicia) vs. Colombia, sentencia de la Corte Interamericana de Derechos Humanos del 14 de noviembre de 2014 (Excepciones preliminares, fondo, reparaciones y costas). Recuperado desde http:// biblio.juridicas.unam.mx/libros/9/4038/10.pdf

González, D. (2008). El derecho a la verdad en situaciones de post- conflicto bélico de carácter no- internacional.

Hoyos, C. (2011). Obligatoriedad y exigibilidad de la Resolución 1325 en Colombia. Recuperado desde http://www.humanas.org.co/archivos/obliexigibilidadresol1325.pdf

López, D. (2006). El derecho de los jueces. Obligatoriedad del precedente constitucional, análisis de sentencias y líneas jurisprudenciales y teoría del derecho judicial. Segunda edición. Legis editores. Bogotá. 2006. 
Muchinik, E. (2003). Acerca de la verdad. Nómadas (Col), núm. 18, mayo, 2003, pp. 56-63. Universidad Central. Bogotá, Colombia

Naciones Unidas, Asamblea General (2007). Resolución 60/255

Naciones Unidas, Asamblea General (2009). Resolución 9/11

Naqvi, Y. (2006). El derecho a la verdad en el derecho internacional: ¿realidad o ficción?

Navarrete, M. (s.f.). El derecho a la verdad. Recuperado desde http://www.observatoriomercosur.org.uy/UserFiles/File/DERECHO_A_LA_VERDAD.pdf

Núñez, R. \& Zuluaga, L. (2012). Estándares internacionales de reparación de violaciones de derechos humanos: principios de implementación en el derecho colombiano. Revista Análisis Internacional.

Organización de Estados Americanos, Centro de Estudios Legales y Sociales (2001). Verdad y justicia. Homenaje a Emilio F. Mignone.

Organización de Estados Americanos, Comisión Interamericana de Derechos Humanos (2014). Derecho a la verdad en América.

Torreblanca, L. (2012). El derecho a la verdad en el ámbito iberoamericano. Ius Humani,Revista de derecho.

Villarreal, Á. F. A. (2007). "Efecto Reflejo": la práctica judicial en relación con el derecho a la verdad en la jurisprudencia de la Corte Interamericana de derechos Humanos. International Law: Revista Colombiana de Derecho Internacional, (10), 131-152. 